\title{
On- and off-premise drinking choices among Indigenous Australians: The influence of socio-spatial factors
}

\section{Introduction}

The geographies of alcohol consumption have been examined by researchers from several different disciplines. Alcohol researchers have investigated spatial and environmental influences on drinking [1], the impact of outlet density [2] and the 'bunching' of particular types of venue $[3,4]$. Australian criminological research has examined for example, the location and type of venue associated with alcohol related assaults [5,6], the regional geography of offending [7] and the policy implications of this [8].

Human geographers have been slower to engage in nuanced empirical studies of the spatialities of drinking and Jayne, Valentine and Holloway suggest that geographical research has under theorised the role of space and place as key constituents of alcohol, drinking and drunkenness [9]. Anthropological studies in Australia and overseas have investigated the social and cultural patterns of the drinking act and their role in sociability and the creation and sustenance of relatedness among Indigenous people [10,11]. It is well known among anthropologists in Australia that in many regions Indigenous people use space and place as ways of differentiating one group from another [12]. This paper uses an anthropological approach to examine the ways in which Indigenous people utilise such differentiation in their drinking arrangements. Choice of place and companions is used to enhance sociability, but also to avoid trouble. However, these socio-spatial choices influence decisions that favour packaged (takeaway) liquor rather than consumption on regulated licensed premises. Attempts to reduce the well-documented harms associated with takeaway liquor and to encourage on-premise drinking have included the establishment of community-owned licensed social clubs and public hotels, with mixed results.

\section{Historical background}

Banning Indigenous patrons from the hotel bar (or serving them from a slot out the back) was the most egregious manifestation of the policy of alcohol prohibition for Indigenous people. Prohibition was just one example of the racial segregation in Australia that separated people spatially, socially and economically [13]. It created geographies of drinking and drunkenness separating Indigenous and non-Indigenous Australiansthe vestiges of which still exist today. Prohibition affected all individuals of Aboriginal descent as well as Torres Strait and Pacific Islanders. Racially based alcohol restrictions were introduced and administered by each state, commencing with New South Wales in 1838. The consequence was public drinking with supplies purloined when and how people could get hold of them, precipitating an Australian anxiety about these public displays that has persisted ever since.

The public hotel was the social hub of every Australian country town, and for Aboriginal people exclusion constituted a profound social disability as well as a humiliation. Banning hotel drinking was the aspect of prohibition that rankled most, especially among those who worked alongside whites [14]. Aboriginal drinking was often binge drinking: racially segregated, unmonitored and beyond the normal checks and balances (however, rudimentary) that existed in the bounded space of licensed premises. Drinking in the open enabled a culture of unconstrained consumption to flourish. It also made it easier for Aboriginal drinkers to put pressure on relatives - the practice of 'demand sharing' [15] in which close kin and consociates share and exchange their resources.

The repeal of restrictions took place state by state with the last restrictions repealed in Western Australia in 1972, less than 40 years ago. Not surprisingly, hotels and licensed clubs became targets for Aboriginal

Maggie Brady PhD, ARC Fellow. Dr Maggie Brady, Centre for Aboriginal Economic Policy Research, Hanna Neumann Building 21, Australian National University, ACT 0200, Australia. Tel: +61 26125 4796; Fax: +61 26125 9730; E-mail: maggie.brady@anu.edu.au

Received 5 March 2009; accepted for publication 12 October 2009. 
activism over the right to drink as equals [16], and once prohibition was repealed, in urban and in rural areas the hotel was the real and symbolic site where people drank in order to proclaim their equality. In March 1965 for example, not long after the anti-discrimination 'Freedom Ride' in outback New South Wales, Aboriginal activist Charles Perkins led a large group of Aboriginal men in a defiant 'drink-in' at the Burlington Hotel, Sydney.

In the early 1970s in Bourke (a small town in rural New South Wales), social change activist $\mathrm{Dr}$ Max Kamien observed that the hotel provided Aboriginal people with the opportunity to be on equal terms with whites. The premises were also comfortable by comparison with most Aboriginal housing at the time. More significantly, Kamien observed that drinking in the hotel alongside non-Indigenous people began to make inroads into the all-or-nothing style of consumption that had developed under prohibition. He noted that people began to shift from finishing the bottle to 'milder social habits' [17]. This was not the case everywhere however, and in the 1970s, at bars in Alice Springs, such as the 'snake pit' at the Riverside Hotel (where Aboriginal drinkers became predominant), chairs became weapons and had to be removed; and the square yard at the Hotel Alice became known locally as 'Madison Square Gardens' because of the number of fights there [Personal communication, Dick Kimber (historian), Alice Springs 1/8/08] (cf [18]).

\section{On-premise drinking versus packaged alcohol}

A decline in drinking on hotel premises and a growth in consumption of packaged alcohol have occurred among all Australians since the 1970s, influenced by factors, such as industry deregulation, greater competition, supermarket sales, drive-in bottle shops, random breath testing, competitive prices, changed drinking cultures and technology $[19,20]$. Technological innovations in the 1960s and 1970s, such as ring-pull cans, rip-top stubbies [21] and the wine cask, have been designed to make it easy for customers buying takeaway alcohol. The convenient air-tight wine bladder in a box, the 'cask', was invented in Australia, became popular for home consumption in the general population [22] and rapidly found its way into Aboriginal drinking circles [23] where it is colloquially known as the 'green suitcase' or 'lady in boat' (after the illustration on the box produced by one wine brand) [24].

For many Aboriginal drinkers now-particularly in rural and remote Australia - the public hotel is not usually the drinking location of choice and takeaways have taken over. Today the political and regulatory debate within the Indigenous community over availability is not about access to on-premise sales as was the case in the 1960s-these struggles today almost invariably concern the availability of takeaway alcohol $[25,26]$ because Aboriginal people are well aware of the fact that for them, alcohol-related trouble (both social and physical) is primarily associated with takeaway liquor, not with on-premise consumption [27]. In Bourke Shire, for example, where there are consistently higher rates of alcohol-related crime than in other New South Wales Local Government Areas [7], there has been a documented shift from drinking on hotel premises to off-premise consumption. Between 2002-2003 and 2007-2008 there were reductions in the rate of assaults on licensed premises, but arrests following consumption in the home increased by $48 \%$ [28].

\section{Social, cultural and spatial issues}

It is hardly surprising that Aboriginal drinkers, like other Australians, made the switch to buying alcohol for off-premise consumption, and for similar reasons: because of lower prices, easy availability and bulk buying. Structural, political and social circumstances, including discriminatory practices and dress requirements, have also led Aboriginal drinkers to locations other than licensed venues [29]. There are, however, some less obvious reasons why many in the Aboriginal population have abandoned hotel-drinking since the heady days that followed the repeal of race-based restrictions. These reasons have to do with the sociocultural spatialities of alcohol consumption.

At a community alcohol forum in June 2008, the Bourke Alcohol Working Group (part of the local Community Drug Action Team) reported the shift from hotel to home-based drinking, together with the reasons given by Aboriginal people for preferring to drink at home (with takeaways), rather than in a hotel. At home, they said, there were fewer restrictions on behaviour, packaged alcohol was cheaper, and the hotels lacked entertainment and food, segregated Aboriginal and non-Aboriginal people and were unpleasant due to noise, smell and poor facilities. Aboriginal respondents also explained that drinking takeaway alcohol allowed for people to stay together with a chosen group while drinking [28]. The ability to select, recruit and maintain particular companions for the act of drinking also emerged as an issue during research undertaken by the author in Elliott, Northern Territory in 2008. Elliott (pop 658) is a small town on the main highway north of Tennant Creek, with a long history of local Aboriginal activism around alcohol issues. Despite the existence of a licensed public hotel in the town, during my research there the (majority) Aboriginal population preferred to make their own drinking arrangements with their self-imposed takeaway ration of two six-packs of full strength beer. In an unusual 
example of home-based consumption that appeared to work well (unlike the reports from Bourke, and with the assistance of local police), the Aboriginal residents of the two 'town camps' just north and south of the town chose to drink in the (fenced and gated) backyards of their houses. Drinkers reported that in this setting they drank only with invited guests and were able to dissuade others from joining in. One resident explained, 'If you're at home [there is] no humbugging, they share. They tell friends they can share. If they were not invited, they wouldn't bother'. It was sensible, said one woman, to drink with people in situations where 'you trust them and they trust you'. Another resident explained that drinking within the fenced area at home provided some protection from troublesome others ('We keep to ourself. If we mix in, there's trouble there already'), including those who came 'loafing for grog'. Food and water were available at home, some nondrinkers were present, and children were monitored. Significantly, when this arrangement became illegal as a result of new Prescribed Areas legislation imposed by the Australian Government in September 2007 $[30,31]$, drinkers did not choose to reconvene on-premise at the Elliott Hotel, but took their takeaway ration and promptly attempted to recreate their chosen drinking groups by setting up small drinking spots out in the scrub beyond the town boundaries. These were less comfortable physical circumstances, and with no fences or boundaries people had difficulty in maintaining the exclusivity of their groups.

The research highlighted the determination of Elliott community members to differentiate themselves into select groups when drinking, in order to pre-empt conflict by exerting what control they could over who was included or excluded (i.e. not 'mixing in'). As was the case in Bourke, it was takeaway alcohol that made these strategies possible, whereas drinking at the cramped and single hotel bar in Elliott did not. In the past, there had been two bars, giving people greater choice. In both Elliott and in Bourke, community members perceived the hotels to be pricey, racially segregated or frankly racist, and to offer limited choices of space within which to arrange themselves. Hotels in Alice Springs for example, that once had big rooms, beer gardens and 'plenty room' to move around, are now perceived by Aboriginal people to be 'closed in'. 'You might not want to meet someone' observed a long-term resident.

\section{Discussion}

It is culturally normative for Aboriginal people to use space and separation as a way of maintaining flexibility in social arrangements and as a means of dealing with community tensions. Historically, people would camp close by those to whom they were related, further away from those they did not get on with, and orient their camps towards the country from whence they came [32]. Drinking in selective groups is a variation on this theme. Recruiting drinking consociates, maintaining a boundary and setting up an exclusive 'pitch' [33] have been documented as attempts to forestall encounters with troublesome or unpredictable outsiders: an Indigenous harm reduction strategy. Such strategising reveals that among these Aboriginal people, alcohol expectancies are that drinking often turns into 'drunken changes-for-the-worse' [34,35]. There is cultural foreknowledge [36] that with a combination of factors, things easily get out of hand. With experience of prolonged fieldwork in the Aboriginal camps south of Darwin, anthropologist Basil Sansom pointed out that 'grogging of itself is dangerous', especially open air drinking in the company of relative strangers [33].

Despite these grass-roots spatial strategies for mitigating alcohol-related trouble, they are not sufficient to change a culture of determined intoxication, and offpremise drinking continues to be associated with the most serious health and social consequences. The evidence for this is demonstrated by the marked decrease in negative sequelae in instances where off-premise supplies are rigorously restricted or even cut off entirely. A 12 month evaluation of the cessation of packaged alcohol sales in the remote town of Fitzroy Crossing, Western Australia is one recent example of this $[37,38]$.

Weaning Aboriginal drinkers away from their preferred but unsupervised outdoor locations and attracting drinkers into well-regulated licensed settings is a goal promulgated by government agencies, such as licensing authorities [39], industry groups, such as the Australian Hotels Association, and by some Aboriginal non-government organisations [40]. They argue that it is only on licensed premises, which are subject to enforceable laws [6], that drinking behaviour can be monitored, and that on-premise drinking will facilitate changes in a drinking culture presently lacking constraint. This is because bar staff are trained in responsible service of alcohol (and this is easier to put in practice than in bottle shop settings), food and entertainment are available, and because premises can even instigate preventive and harm reduction interventions [41]. Above all, licensed premises constitute a drinking environment bearing at least some expectations of a basic standard of comportment.

Ranged against these arguments is the considerable volume of research documenting the rarity of prosecuted breaches against licensees (as opposed to patrons) [42]; the identification of high-risk premises [5,29]; the impact of extended trading hours [43]; and the discriminatory practices and dress codes that still affect Indigenous people [44]. International research also documents widespread aggression in bars [18] and 
the practice of 'pre drinking' - planned drinking sessions undertaken prior to going out to licensed premises [45].

Attempts have been made in the past to manage these negative factors through the establishment of social clubs and beer canteens operated by Aboriginal community councils. Several were established in the late 1960s-1970s in the hope that if Aboriginal organisations had local control over the rationing of alcohol then moderate drinking would develop. This 'wet' position was enthusiastically promulgated to a government Standing Committee in 1976-1977, although there were plenty of 'drys' arguing against it [46]. Today the Northern Territory currently has eight such clubs located in discrete Aboriginal communities, and in Queensland until 2008 there were nine canteens and taverns in remote communities operated by local Aboriginal councils. The available evidence for their effectiveness, however, is not positive [11,47]. It shows that overall these within-community premises do not curb takeaway purchases, reduce travel to nearby towns, or promote responsible drinking, but contribute to a pervasive culture of heavy drinking and place Aboriginal Councils in an invidious conflict of interest $[48,49]$. In 1993 the Tangentyere Council, an Aboriginal 'town council' in Alice Springs, was the driving force behind the purchase of a licensed social club on the south side of town: the Tyeweretye Club. It was designed to offer an alternative to takeaway consumption and a setting in which Aboriginal people would feel comfortable and have 'ownership'. Significantly, in view of the earlier discussion regarding cultural spatialities and the selection of drinking companions, the original proposal arising from community consultations was to establish four different clubs, north, south, east and west, 'where different language groups could go without running into each other', thus recognising the internal differentiations within the so-called Aboriginal 'community' of Alice Springs, and the town's many visitors [40]. But despite its goals of fostering responsible drinking, providing food and entertainment and a beer garden, the Club was controversial and ultimately closed down in April 2005, one major reason for its demise being that when the town's bottle shops opened at $2 \mathrm{pm}$ the Club's patrons vacated the premises. It became an example of 'pre-drinking' [45] in reverse: on-premise drinking prior to off-premise drinking.

As well as these social clubs, Indigenous community corporations partly or wholly own several licensed public hotels in Australia, including two in South Australia, one in Western Australia and three in the Northern Territory. All are in small rural towns and cater to locals as well as tourists. These are intended to be social enterprises [50] with participatory governance structures, distribution of profits for community benefit, social aims, such as creating jobs, and responsiveness to community desires to implement restrictions on sales if and when these become harmful. In 1975, for example, the first action taken by the first Aboriginal community to purchase a hotel (in Finke, South Australia) had been to ban takeaway sales of wine and spirits.

These aims mimic the principles that guide other non-Indigenous community-owned hotels notably in South Australia where there are 11 such premises. The oldest of these is the Renmark Community Hotel which was licensed to a locally elected committee in 1897. Its philosophical origins lie in the Swedish Gothenburg System - a 19th century model of municipal or community liquor control in which the managers of bars had no pecuniary interest in the sale of alcohol. This idea of 'disinterested management' was aimed at stopping publicans from pushing sales on customers, thus eliminating political influence on the liquor trade, as well as controlling drunkenness [51].

However, the Aboriginal community-owned hotels do not have 'disinterested' management. A key rationale for their existence is to make a profit that can be distributed for the benefit of the community. A common way of expressing this is the idea of 'keeping the money in the community'. Ideally, owning the premises also enables Aboriginal groups to eradicate irresponsible or discriminatory service and to create appropriate amenities. The only 'evaluation' of such an enterprise to date emerged in 2007 in the form of a coronial enquiry which found that a hotel in Fitzroy Crossing, Western Australia, part-owned by an Aboriginal trust, had failed the community it set out to benefit. The inquest concluded that takeaway alcohol sold by the hotel was associated with 11 out of 22 Aboriginal deaths under investigation, and that the hotel's financial distributions had not reached the intended beneficiaries [52]. This was despite earlier informal reports suggesting modest benefits as a result of community ownership, such as implementing requested changes to hours of takeaway sales and selling only light beer during carnivals, sporting events or funerals [24]. In addition, the hotel had instigated a number of self-imposed liquor restrictions to manage heavy drinking. An enforced prohibition of sales of all packaged alcohol exceeding $2.7 \%$ ethanol from the premises in 2007 has prompted a significant increase in patronage of the hotel bar by local residents [37].

\section{Conclusion}

If on-premise options (such as Indigenous social clubs or community-owned public hotels) are to be a viable means of diminishing the high levels of alcohol-related harm associated with unmonitored outdoor consumption of packaged alcohol, then a number of risks and 
benefits require attention. The risks are associated with poor governance and management and the suitability and training of bar staff; the physical environment, which could intensify aggression and violence; the need to provide settings which satisfy Indigenous desires to select their drinking companions; and the pressure on such enterprises to produce profits for the community's benefit, which could lead to reluctance to implement limits on sales for public health reasons. A further risk is that such premises endorse and reinforce what are (in some instances) racially segregated drinking settings. The benefits on the other hand include stimulating Indigenous community engagement with, and debate over, alcohol availability; creating a sociable and culturally comfortable context for the consumption of alcohol with food; and the expectation that these settings will habituate patrons into less harmful patterns of alcohol consumption.

\section{Acknowledgements}

An earlier version of the paper was presented at the 40th Anniversary Symposium of the NSW Bureau of Crime Statistics and Research 18-19 February 2009. The research and interviews reported here form part of a wider ARC-funded study (DP0772382) with Dr Boyd Hunter as co-investigator. Research at Elliott in 2008 was undertaken with my colleague Dr Carol Watson whom I thank for her insights.

Maggie Brady
ARC Fellow
Maggie Brady, Centre for Aboriginal Economic Policy
Research, Hanna Neumann Building 21, Australian
National University, ACT 0200, Australia
E-mail: maggie.brady@anu.edu.au

\section{References}

[1] Zinberg N. Drug, set and setting: the basis for controlled intoxicant use. New Haven: Yale University Press, 1984.

[2] Livingston $M$. Alcohol outlet density and assault: a spatial analysis. Addiction 2008;103:619-28.

[3] Livingston M, Chikritzhs T, Room R. Changing the density of alcohol outlets to reduce alcohol-related problems. Drug Alcohol Rev 2007;26:557-66.

[4] LaVeist TA, Wallace JM. Health risk and inequitable distribution of liquor stores in an African American neighbourhood. Soc Sci Med 2000;51:613-17.

[5] Briscoe S, Donnelly N. Assaults on licensed premises in inner-urban areas. Alcohol Studies Bulletin no. 2. Sydney: Bureau of Crime Statistics and Research, 2001.

[6] Wiggers J, Jauncey M, Considine R, et al. Strategies and outcomes in translating alcohol harm reduction research into practice: the Alcohol Linking Program. Drug Alcohol Rev 2004;23:355-64.

[7] Briscoe S, Donnelly N. Temporal and regional aspects of alcohol-related violence and disorder. Alcohol Studies
Bulletin no. 1. Sydney: Bureau of Crime Statistics and Research, 2001.

[8] Tyler W. Race, crime and region: the socio-spatial dynamics of Aboriginal offending. J Sociol 1998;34:152-69.

[9] Jayne M, Valentine G, Holloway SL. Geographies of alcohol, drinking and drunkenness: a review of progress. Prog Hum Geogr 2008;32:247-63.

[10] Collmann J. Fringe-dwellers and welfare. The Aboriginal response to the bureaucracy. St Lucia: University of Queensland Press, 1988.

[11] Martin DF. The supply of alcohol in remote Aboriginal communities: potential policy directions from Cape York. CAEPR Discussion Paper 162. Canberra: Centre for Aboriginal Economic Policy Research, Australian National University, 1998.

[12] Brady M, Palmer K. Alcohol in the Outback. Darwin: North Australia Research Unit, 1984.

[13] Byrne DR. Nervous landscapes: race and space in Australia. J Soc Archaeol 2003;3:169-93.

[14] Brady M. First taste. How indigenous Australians learned about grog. Canberra: AER Foundation, 2008.

[15] Peterson N. Demand sharing: reciprocity and the pressure for generosity among foragers. Am Anthropol 1993;95:860 74.

[16] Curthoys A. Freedom ride. A freedom rider remembers. Sydney: Allen \& Unwin, 2002.

[17] Kamien M. The Dark People of Bourke. A study of planned social change. Canberra: Australian Institute of Aboriginal Studies: 1978.

[18] Graham K, LaRoque L, Yetman R, Ross TJ, Guistra E. Aggression and barroom environments. J Stud Alcohol 1980;41:468-85.

[19] Marsden Jacob Associates. Identifying a framework for regulation in packaged liquor retailing. Report prepared for the National Competition Council as part of the NCC Occasional Series. Melbourne: Marsden Jacob Associates, 2005: Available at: http://www.ncp.ncc.gov.au/docs/PIReMJ-003. pdf (Accessed 4 January 2010).

[20] South D. Changing drinking and driving patterns: a case history. In: Vernon J, ed. Alcohol and crime. Canberra: Australian Institute of Criminology, 1990:107-19. Available at: http://www.aic.gov.au/publications/previous $\% 20$ series/proceedings/1-27/ /media/publications/ proceedings/01/south.ashx (Accessed 4 January 2010).

[21] Welborn S. Swan. The history of a brewery. Perth: UWA Press, 1987.

[22] Stockwell T, Crosbie D. Supply and demand for alcohol in Australia: relationships between industry structures, regulation and the marketplace. Int J Drug Policy 2001;12:139-52.

[23] Gray D, Chikritzhs T. Regional variation in alcohol consumption in the Northern Territory. Aust N Z J Public Health 2000;24:35-8.

[24] Brady M. The grog book. Strengthening indigenous community action on alcohol. Canberra: Department of Health and Ageing, 2005.

[25] Gray D, Saggers S. Indigenous Australian alcohol and other drug issues: research from the national drug research institute. Perth: Curtin University, 2002.

[26] Douglas M. Restrictions on the hours of sale of alcohol in a small community: a beneficial impact. Aust N Z J Public Health 1998;22:714-19.

[27] Brady M, Byrne J, Henderson G. 'Which bloke would stand up for Yalata?' The struggle of an Aboriginal community to control the availability of alcohol. Aust Aborig Stud 2003;2:62-71. 
[28] Kristine Battye Consulting. The impact of alcohol in the Bourke Community. Discussion paper for the Bourke Community Drug Action Team. Orange, New South Wales, 2008.

[29] Doherty SJ, Roche AM. Alcohol and licensed premises: best practice in policing. A monograph for police and policy makers. Adelaide: Australasian Centre for Policing Research, 2003.

[30] Altman J, Hinkson M, eds. Coercive reconciliation. Stabilise, normalise, exit Aboriginal Australia. Melbourne: Arena Publications Association, 2007.

[31] Centre for Aboriginal Economic Policy Research. Submission to NTER Review, 2008 by Maggie Brady, Carol Watson. Available at: http://www.nterreview.gov.au/subs/ nter_review_report/123_caepr/123_Centre_for_Aboriginal Economic.htm (accessed 4 January 2010).

[32] Goodall $\mathrm{H}$. Invasion to embassy. Land in aboriginal politics in New South Wales, 1770-1972. Sydney: Allen and Unwin, 1996.

[33] Sansom B. The camp at Wallaby Cross. Aboriginal fringe dwellers in Darwin.Canberra: Australian Institute of Aboriginal Studies, 1980.

[34] MacAndrew C, Edgerton RB. Drunken comportment. A social explanation. Chicago: Aldine Publishing Co, 1969.

[35] Jones BT, Corbin W, Fromme K. A review of expectancy theory and alcohol consumption. Addiction 2001;96:5772 .

[36] Room R. Intoxication and bad behaviour: understanding cultural differences in the link. Soc Sci Med 2001;53:18998.

[37] University of Notre Dame Australia. An evaluation of the effects of alcohol restrictions in Fitzroy Crossing relating to measurable health and social outcomes, community perceptions and alcohol related behaviours after a 12 month period. Broome, University of Notre Dame, 2009. Available at: http://www.dao.health.wa.gov.au/IntheMedia/FitzroyValley LiquorRestrictionReport/tabid/237/Default.aspx (accessed 4 January 2010).

[38] Gray D, Saggers S, Sputore B, Bourbon D. What works? A review of evaluated alcohol misuse interventions among Aboriginal Australians. Addiction 2000;95:11-22.

[39] Northern Territory Licensing Commission. Reasons for decision. Review of the declaration of Alice Springs township as public restricted [sic.] And review of alcohol supply measures introduced in Alice Springs. 12 August 2009. Darwin: Northern Territory Licensing Commission, 2009.
[40] Tilmouth W. Evidence to the House of Representatives Standing Committee on Aboriginal and Torres Strait Islander Affairs inquiry: Needs of urban dwelling Aboriginal and Torres Strait Islander People. Hansard 1 May 2001, Alice Springs.

[41] Graham K. Preventive interventions for on-premise drinking. A promising but underresearched area of prevention. Contemp Drug Probl 2000;27:593-668.

[42] Briscoe S, Donnelly N. Liquor licensing enforcement activity in New South Wales. Alc Studs Bull 4, New South Wales Bureau of Crime Statistics and Research, 2003.

[43] Chikritzhs T, Stockwell T, Masters L. Evaluation of the public health and safety impact of extended trading permits for Perth hotels and nightclubs. Perth: National Drug Research Institute report, 1997.

[44] Gray D, Drandich M, Moore L, Wilkes T, Riley R, Davies S. Aboriginal wellbeing and liquor licensing legislation in Western Australia. Aust J Public Health 1995;19:177-85.

[45] Wells S, Graham K, Purcell J. The widespread practice of 'predrinking' or 'pregaming' before going on to public establishments. Addiction 2009;104:4-9.

[46] Brady M. Indigenous Australia and alcohol policy. Meeting difference with indifference. Sydney: University of New South Wales Press, 2004.

[47] Fitzgerald T. Cape York Justice Study Volume 2. The situation of Cape York Indigenous Communities. Brisbane: Queensland Department of Community Services, 2001. Available at: http://www.communityservices.qld.gov.au/ community/publications/capeyork.html (accessed 4 January 2010).

[48] d'Abbs PHN. Out of sight, out of mind? Licensed clubs in remote Aboriginal communities. Aust N Z J Public Health 1998;22:679-84.

[49] Brady M. Out of the shadow of prohibition. In: Altman J, Hinkson M, eds. Coercive reconciliation. Melbourne: Arena Publications Association, 2007:185-94.

[50] Defourny J, Nyssens M. Defining social enterprise. In: Nyssens M, ed. Social Enterprise. At the crossroads of market, public policies and civil society. London and New York: Routledge, 2006:3-26.

[51] Greenaway J. Policy learning and the drink question in Britain 1850-1950. Polit Stud 1998;XLVI:903-18.

[52] State Coroner Western Australia. Inquest into the deaths of Edward John Riley \& 21 others. Record of Investigation into deaths by Alastair Neil Hope, State Coroner, 25 February, Perth: 2008. 